\title{
HUMANIZAÇÃO NA PRODUÇÃO DO CUIDADO À CRIANÇA HOSPITALIZADA: CONCEPÇÃO DA EQUIPE DE ENFERMAGEM
}

\author{
HUMANIZING CARE FOR HOSPITALIZED CHILDREN: DESIGNING THE NURSING TEAM
}

\author{
Ilvana Lima Verde Gomes ${ }^{1}$ \\ Nair Assunta Corso Câmara ${ }^{2}$ \\ Guesa Maria Dantas Lélis ${ }^{3}$ \\ Gilvânia Ferreira Castro Grangeiro ${ }^{4}$ \\ Maria Salete Bessa Jorge ${ }^{5}$
}

Resumo Objetivou-se compreender a humanização das ações de enfermagem na concepção da equipe de enfermagem, apreendendo o significado de humanização na prática. Para isso, utilizou-se de estudo descritivo exploratório, com análise qualitativa, tendo como técnica a entrevista semiestruturada. Foram realizadas 12 entrevistas com cinco enfermeiros e sete auxiliares de enfermagem de um hospital público de Fortaleza, Ceará, em 2005. A análise dos dados foi feita após múltiplas leituras e interpretada de acordo com a análise de conteúdo, da qual surgiram duas temáticas: humanização - tratar bem, cuidar e respeitar; e vivenciando a humanização. Conclui-se que a equipe de enfermagem, embora tenha explicitado o conceito de humanização, apresentou noção acerca do significado e demonstrou a importância de cuidar além da doença, respeitando a criança como ser humano. Houve também a preocupação com a ausência de material, o que na visão de alguns sujeitos dificultaria a prestação de cuidado digno, menos doloroso e com resolutividade.

Palavras-chave humanização da assistência; criança hospitalizada; equipe de enfermagem.
Abstract The goal was to understand the humanization of the nursing actions while designing the nursing staff, learning the meaning of humanization in practice. To achieve this, an exploratory descriptive study with qualitative analysis was used based on the semistructured interview technique. Twelve interviews were conducted with five nurses and seven nursing assistants in a public hospital in Fortaleza, Brazil, in 2005. Data analysis was performed after multiple readings had been made, and the results were interpreted based on the analysis of the content, a process leading to two themes: humanization - treat well, care and respect; and experiencing humanization. It was concluded that the nursing staff, although having made the humanization concept explicit, revealed to be aware of the concept and showed the importance of looking beyond the disease, respecting the child as a human being. There was also concern with the lack of material, which in the view of some subjects rendered it difficult to provide decent, less painful care with resolution.

Keywords humanization of assistance; hospitalized child; nursing staff. 


\section{Introdução}

A humanização do cuidado é um tema que ao longo dos anos vem ecoando pelos corredores da saúde, porém na sua forma concreta, em nosso perceber, ainda precisa avançar muito para que seja uma prática rotineira nos serviços de saúde.

Humanizar, segundo Ferreira (1999, p. 1.064), é "tornar humano; dar condição humana a; humanar. Tornar benévolo, afável, tratável. Fazer adquirir hábitos sociais polidos; civilizar". Assim, compreende-se que o verbo tornar pressupõe construção em processo, o que significa que o ser humano, apesar da natureza humana, necessita construir e aperfeiçoar esta mesma natureza para poder relacionar-se com o outro de forma afável, tratável etc.

A noção de 'humanização', geralmente, é empregada para a

forma de assistência que valorize a qualidade do cuidado do ponto de vista técnico, associada ao reconhecimento dos direitos do paciente, de sua subjetividade e referências culturais. Implica ainda a valorização do profissional e do diálogo intra e interequipes (Deslandes, 2004, p. 8).

Em face desse processo de humanização, em maio de 2000 o Ministério da Saúde regulamentou o Programa Nacional de Humanização da Assistência Hospitalar (PNHAH) e, em 2004, substituiu o PNHAH pela Política Nacional de Humanização (PNH). A PNH é transversal, atravessa as diferentes ações e instâncias gestoras do Sistema Único de Saúde (SUS), e nesta política, humanização é entendida como valorização dos diversos sujeitos envolvidos no processo de produção de saúde: usuários, trabalhadores e gestores. Esses valores são norteados pela autonomia e pelo protagonismo dos sujeitos, a corresponsabilidade entre eles, o estabelecimento de vínculos solidários e a participação coletiva no processo de gestão (Brasil, 2004).

Não se pode negar a preocupação do governo quanto à humanização do cuidado nas unidades de saúde, porém há muito a ser procedido.

Muitos projetos acerca da humanização estão sendo desenvolvidos no Brasil, tais como grupo operativo com pacientes ontológicos, na pediatria e com pacientes renais (Rim-arte), e controle do nível de estresse dos funcionários por meio da massagem terapêutica. No entanto, cogita-se na humanização no conjunto de relações que se estabelecem nas instituições: profissional-paciente, recepção-paciente, profissional-equipe, profissionalinstituição e outras (Martins, 2003).

Humanização também significa, ou precisa significar, melhoria das condições de trabalho do cuidador. É uma necessidade do hospital cuidar do cuidador, ou seja, cuidar para que o profissional de saúde possa desem- 
penhar suas funções de maneira harmoniosa, sadia, sem que o estresse o afete de maneira que prejudique seu desempenho técnico, afetivo e sua saúde física e mental.

(...) cuidador é todo aquele que vivencia o ato de cuidar e expressa esta experiência em diferentes momentos e situações, pode realizar-se com diferentes pessoas em ocasiões distintas de suas vidas (Costenaro e Lacerda, 2001, p. 17).

As condições de trabalho influem na satisfação do profissional em relação ao seu trabalho. Segundo Martins (2003), a atividade assistencial se constitui, para os profissionais de saúde, em fonte de gratificação e de estresse. Segundo a autora, os fatores gratificantes seriam diagnosticar e tratar adequadamente, curar, prevenir, educar, aconselhar, sentir-se competente, receber reconhecimento. Os fatores estressantes seriam ter contato frequente com a dor e o sofrimento, lidar com as expectativas dos pacientes e familiares; atender pacientes 'difíceis' (não aderentes ao tratamento, hostis, agressivos, depressivos, autodestrutivos), lidar com as limitações do conhecimento científico. Acrescenta-se a ausência de material e equipamentos, de remédios, a superlotação de doentes e a carência de pessoal para atendê-los.

Os fatores estressantes são também fatores que dificultam o atendimento, o acolhimento, vínculo que se desenvolve entre o profissional de saúde e o paciente/família - além da sobrecarga, que leva o profissional a se sentir culpado por não satisfazer as necessidades do paciente ou então se mostrar incapaz de fazê-lo, já que não dispõe de material ou pessoal suficiente para isso.

Silva (2003), em estudo sobre absenteísmo na equipe de enfermagem da emergência de um hospital geral, detectou que as causas de maior estresse para os sujeitos são: número reduzido dos profissionais de enfermagem e excesso de doentes no corredor. Isto motiva o profissional a despender mais esforço, o que provoca cansaço físico e mental.

Além da infraestrutura, há a necessidade de cuidar do emocional do cuidador. Fraga (1993), em estudo sobre a prática da enfermagem em hospitais psiquiátricos, destaca alguns pontos mencionados pelos sujeitos da pesquisa, os quais, a nosso ver, são relevantes para outros hospitais. Um deles relaciona-se, sobretudo, à equipe de enfermagem, podendo referir-se, também, a outros profissionais de saúde. Quando ocorre um período longo de internação, há uma proximidade física e emocional do profissional com o doente e sua família. Portanto, para 'humanizar' a assistência hospitalar é preciso haver o cuidado com a saúde física e mental dos profissionais de saúde.

Desse modo, esta pesquisa objetivou compreender a humanização das ações de enfermagem na concepção da equipe de enfermagem, apreendendo o significado de humanização na prática. 


\section{Caminhos da pesquisa}

A pesquisa foi descritiva e exploratória, ancorando-se em uma abordagem qualitativa. A pesquisa exploratória objetiva explorar aspectos de uma situação não conhecida, para obter mais informações sobre o objetivo, possibilitando familiarizar-se com pessoas e suas preocupações; e a descritiva objetiva identificar e descrever as características de um determinado fenômeno ou situação não conhecidos (Triviños, 1987; Leopardi, 2002; Deslauriers e Kérisit, 2008).

A metodologia qualitativa é, consoante Minayo (1993), destinada a uma abordagem que se afirma no campo da subjetividade, com o universo de significados, crenças e valores, entre outros aspectos. Leopardi (2002) corrobora o que diz Minayo (1993), já que na pesquisa qualitativa tenta-se compreender o problema na perspectiva dos sujeitos que o vivenciam, ou parte da sua vida diária, seus sentimentos e desejos, bem como na perspectiva do pesquisador.

$\mathrm{O}$ estudo foi desenvolvido na ala de pediatria, aqui denominada de $\mathrm{X}$, de um hospital geral, público, de Fortaleza, gerenciado pelo Estado e de referência para toda a região metropolitana de Fortaleza, interior do Estado e outros estados.

A Ala X do setor pediátrico encontrava-se no terceiro andar do hospital, recebia pacientes clínicos e cirúrgicos de diversas especialidades, como ortopedia, otorrinolaringologia, plástica, cirurgia infantil, embolização, urologia. Possuía 34 leitos, um posto de enfermagem, uma sala de prescrição, uma sala de procedimentos de enfermagem e médicos, uma sala de terapia ocupacional para as crianças e acompanhantes e uma copa. O setor dispunha de uma televisão para as crianças e os acompanhantes. A equipe de enfermagem, por turnos, para atender a esses pacientes era composta de uma enfermeira, três auxiliares, um maqueiro e uma auxiliar operacional de serviços diversos - estes dois últimos, somente no período diurno.

Os sujeitos foram os cinco enfermeiros e sete auxiliares dos turnos diurno e noturno que estavam de plantão nos dias da pesquisa e concordaram em participar da entrevista, assinando o Termo de Consentimento Livre e Esclarecido. As identidades dos sujeitos foram mantidas em sigilo, sendo eles identificados pela letra $S$ de sujeito, seguidos de número de ordem.

Como estratégia de coleta de dados, utilizou-se a entrevista semiestruturada, que foi gravada. Usou-se o diário de campo para registrar aspectos que surgiram e foram relevantes para a pesquisa. O roteiro da entrevista com os participantes constou de um item de identificação: iniciais, idade, vínculo empregatício, anos de formação, outros empregos, jornada de trabalho no hospital e em outro emprego, estado civil e número de filhos.

O segundo item constou de duas perguntas: o que se entende por saúde? Como você vivencia a humanização no seu setor? 
Para análise e interpretação dos dados, utilizou-se a técnica de análise de conteúdo tipo categorial temática de Bardin (2009), a qual apresenta os seguintes passos: pré-análise - organização do corpus (documentos) para análise, leitura flutuante, escolha das unidades de análise (unidade de registro [frase] e unidade de contexto [parágrafo]), leitura exaustiva, recorte de trechos de fala; elaboração de subcategorias e de categorias, posteriormente de temáticas.

\section{Resultados}

Os resultados apontaram para duas categorias, as quais foram ilustradas com trechos de falas e articuladas com a literatura pertinente.

\section{Humanização: tratar bem, cuidar e respeitar}

Para a equipe de enfermagem pesquisada, humanização em saúde significava cuidar, respeitar e tratar bem as crianças:

A humanização é tratar a criança não só como paciente, mas como ser humano. É você ter a dedicação com relação ao teu trabalho para que ele saia bem feito (S2).

A humanização em saúde requer cuidados com o paciente e não só fazer procedimentos sem saber o que o paciente sente, como ele está emocionalmente, se ele está sendo bem atendido, cuidado (S4).

A palavra cuidado remete ao filósofo alemão Martin Heidegger, em cuja obra Ser e tempo identificava o cuidado como "um fenômeno ontológicoexistencial básico" (Heidegger, 1989, p. 261), e do ponto de vista existencial, o cuidado (cura) "se acha a priori, antes de toda atitude e situação do ser humano (pre-sença), o que sempre significa dizer que ele(a) se acha em toda atitude e situação de fato" (Heidegger, 1989, p. 258).

De modo geral, abordar o cuidado de saúde ou cuidado em saúde atribui ao termo um sentido já consagrado no senso comum, o de um conjunto de procedimentos tecnicamente orientados para o bom êxito de um determinado tratamento. Porém, cuidado, do latim cura, em uma forma mais antiga, coera, era usado nas relações de amor e amizade, expressando atitude de desvelo e preocupação (Ayres, 2006; Boff, 1999).

O cuidado como uma ação integral para o ser humano e do ser humano que vive na busca contínua do cuidado, diante da fragilidade social existente no mundo capitalista, conforme Luz (2004), não é um procedimento técnico simplificado, mas o tratar, o respeitar, o acolher, o atender o ser humano em seu sofrimento (Pinheiro e Guizardi, 2004; Luz, 2004). 
Nestas falas, os profissionais entendem que o cuidado vai além da doença - segundo eles, a humanização do cuidado é ampla, adentra a vida familiar e toda a vida do doente para ajudá-lo na recuperação:

Primeiro o bom atendimento na hospitalização. Oferecer o que melhor o hospital tem em termos de conforto, como de ambiente, de alimentação. Lógico, depois vem a medicação que atenda às necessidades (...). A humanização, também, para mim é se inteirar da vida pessoal do paciente. Conhecer o paciente, quem ele é lá fora e por que chegou até aquela doença, é conhecer a família, o ambiente, para que a gente possa ajudá-lo aqui dentro a ter uma qualidade de vida (S3). [...] também é ter cuidado com a família, dar apoio, porque é a base também para poder [...] ajudar o paciente a se recuperar (S4).

Humanização do cuidado para muitos autores brasileiros, como Mattos (2001), Pinheiro, Cecílio e Merhy, entre outros, aparece como sinônimo de cuidado integral. Cecílio e Merhy (2003, p. 198) dizem que o cuidado integral dentro do hospital "é o somatório de um grande número de pequenos cuidados parciais que vão se complementando". O cuidado integral transversaliza todo o sistema, é obtido em rede, é multidisciplinar.

No cuidado integral, como proposto por Pinheiro e Guizardi (2004), deve haver o dialogismo como um elemento constitutivo, cuja prática é resultante do embate de muitas vozes sociais; quando eficaz, pode produzir efeitos de polifonia - quando essas vozes se deixam escutar. Mas quando o diálogo é mascarado e apenas uma voz se faz ouvir, acontece a monofonia (Pinheiro e Guizardi, 2004).

Muitas vezes, no tratamento de crianças, os profissionais não conseguem perceber quão profundamente estas se sentem e como as suas defesas falham se os resultados são apavorantes (Winnicott, 1997). Conforme o autor, as "defesas da criança pequena são capazes de lidar com quase tudo que a vida oferece, desde que exista um ambiente amoroso nessa vida e que o fator tempo seja reconhecido" (Winnicott, 1997, p. 83). Geralmente, a falta de preparo do profissional de saúde em cuidar da criança, muitas vezes direcionado somente para a parte técnica do cuidado, inserido no modelo biomédico, não consegue observar a criança como ser humano integral nem perceber o que acontece com o emocional do paciente. Como menciona Sá:

(...) muitas vezes deixamos de perceber aquilo que foge à rotina e aos procedimentos técnicos que envolvem a assistência ao ser humano, como se suas necessidades emocionais não fizessem parte do planejamento da assistência e à promoção do conforto a esse indivíduo (Sá, 2001, p. 11). 
Portanto, a equipe de saúde precisa perceber que a criança é mais que uma pessoa doente ou uma doença; ela é alguém integrante de um enredo familiar, possui necessidades e desejos. Além disso, os profissionais de saúde precisam considerar os aspectos subjetivos da enfermidade na infância, porque o hospital pode se tornar um lugar 'iatrogênico' e promover mais doença do que saúde, tanto nos pacientes quanto nos profissionais (Morsch e Aragão, 2006; Oliveira, 1997; Capobianco, 2003).

\section{Vivenciando a humanização}

A PNH entende humanização, entre outros fatores, como o compromisso com a ambiência e a melhoria das condições de trabalho e de atendimentos. A carência de material e insumos, por exemplo, é por um lado um dos fatores que contribuem para o cuidado humanizado e, por outro, desrespeito ao direito do doente em ter um atendimento resolutivo, com qualidade, preceituado no segundo princípio da Carta dos Direitos dos Usuários da Saúde de 2006 e em documentos como a resolução n. ${ }^{\circ} 41 / 95$, art. 13, e o Estatuto da Criança e do Adolescente (ECA), art. 11 (Brasil, 1991, 1995).

$\mathrm{Na}$ fala percebeu-se desapontamento ou uma inquietação diante da carência de material presente na unidade:

A gente também necessita de um apoio, de um suporte por parte da administração, porque atender bem o paciente é oferecer o melhor para ele aqui no hospital, nas enfermarias, um certo conforto, até melhor do que ele possa ter na casa dele (S4).

A escassez de material na unidade ocasiona um sofrimento no profissional, segundo a fala anterior; também pode interferir na própria evolução da criança ou na sua internação. Desse modo, os discursos influenciam não apenas o direito a "receber todos os recursos terapêuticos disponíveis para o tratamento", mas também o direito a não ser ou permanecer hospitalizado desnecessariamente (Gomes, 2007, p. 186).

Há uma preocupação em minimizar a dor em procedimentos dolorosos, que são frequentes no setor de internação pediátrica, como a punção venosa periférica, porém a ausência de material não permite isso, desgastando às vezes o profissional e, principalmente, a criança e a família:

Uma criança que tem que se puncionar um acesso com um scalp 21 porque não tem um menos calibroso, um jelco 24 , aí você tem que 'furar' com 21 , 19. Isto não é uma condição própria para um setor como a pediatria (S9). 
A preocupação do profissional não está apenas em atender a criança no sentido de realizar procedimentos, mas em seu bem-estar e na sua rápida recuperação, no seu conforto e no de sua família.

Ter a seu dispor material e medicamentos para atender a criança e sua família também ajuda na saúde e no trabalho do profissional, porém não é pela escassez de material e pessoal que ocorre a desumanização no serviço. Há de se buscarem formas de superar a situação e esclarecer a criança e sua família sobre os problemas enfrentados pelo hospital. As falas a seguir mostram que alguns profissionais estão tentando criar meios de superar situações precárias:

Quando eu tento sentir alguma dificuldade, eu já procuro a resolução do problema; eu não deixo me abater junto com o problema, eu sempre tento resolver (S12).

Agora, aí, com relação à falta de trabalho, às vezes dificulta porque (...) às vezes falta a criatividade para você se virar com o que tem, mas dá pra levar (S10).

Essa busca de se resolver o problema com o uso da criatividade demonstra a preocupação do profissional em prestar cuidado humanizado à criança e sua família. As condições de trabalho e a presença de insumos e outros materiais médico-hospitalares são muito importantes para a humanização do cuidado e, principalmente, para o tratamento da criança. De acordo com a Política Nacional de Humanização, é preciso investir na melhoria das condições de trabalho e de atendimento. Às vezes, dentro do hospital, existem máquinas de última geração e faltam medicamentos e materiais para procedimentos, como luvas, seringas, agulhas, ou para lavagem das mãos, o que é fundamental para o controle da infecção hospitalar.

O cuidado integral em saúde aconteceria mediante uma combinação generosa e flexível de tecnologias duras (ligadas a equipamentos, procedimentos), leve-duras (uso de saberes bem estruturados) e leves (relacionais no espaço intersubjetivo do profissional de saúde e paciente). Tecnologia e humanização devem estar combinadas, como ponto de partida para qualquer intervenção hospitalar, no desafio de adotar o lugar do paciente e suas necessidades singulares (Cecílio e Merhy, 2003).

\section{Pontos para reflexão}

A Política Nacional de Humanização (Brasil, 2004) sinaliza o compromisso com a ambiência, as melhorias das condições de trabalho e de atendimento, a valorização dos diferentes sujeitos implicados no processo de produção de saúde: usuários, trabalhadores e gestores. 
Do mesmo modo, na Carta dos Direitos dos Usuários da Saúde, documento lançado em 2006 pelo governo federal (Brasil, 2006), conforme o segundo princípio, todo cidadão tem direito ao atendimento adequado e efetivo. Esse atendimento adequado inclui tecnologia apropriada e condições de trabalho adequadas para os profissionais de saúde.

A humanização do cuidado advém da conscientização do profissional de saúde sobre seu trabalho, sobre os direitos do doente e sobre a importância do trabalho em equipe multidisciplinar, entre outros fatores.

No tocante ao observado, a carência de material e equipamentos na unidade e no hospital muitas vezes resulta em frustração profissional, ao se perceber que essa lacuna pode prolongar o internamento do menor e até ocasionar um sofrimento maior, quando não se dispõe de dispositivos adequados para uma punção venosa, como o exemplo citado.

Percebeu-se que há um interesse da equipe de enfermagem em solucionar os problemas decorrentes da carência de material, não havendo acomodação à situação que se apresenta. Nas falas, os profissionais demonstraram, também, que tinham interesse em conhecer a criança e sua família, e não somente a doença que motivou a internação.

\section{Notas}

1 Enfermeira do Hospital Geral de Fortaleza (HGF) e professora adjunta da Universidade Estadual do Ceará (Uece), Fortaleza, Brasil. Doutora em Saúde Coletiva pelo Instituto de Medicina Social, Universidade do Estado do Rio de Janeiro (IMS/Uerj). <ilverde@uol.com.br>.

Correspondência: Rua J. da Penha, 631, apt. 1.003, CEP 60.110-120, Fortaleza, Ceará, Brasil.

2 Enfermeira do Hospital Geral de Fortaleza (HGF), Fortaleza, Brasil. Mestranda em Saúde Coletiva pela Universidade de Fortaleza (Unifor). <naircorso@ig.com.br>.

3 Enfermeira e diretora de Recursos Humanos do Hospital Geral de Fortaleza (HGF), Fortaleza, Brasil. Especialista em Saúde, Trabalho e Meio Ambiente pela Universidade Federal do Ceará (UFC) <g.lelis@hotmail.com>.

4 Enfermeira e gerente de enfermagem do Hospital Geral de Fortaleza (HGF), Fortaleza, Brasil. Especialista em Enfermagem Médico-Cirúrgica pela Universidade Estadual do Ceará (Uece) e em Gestão Hospitalar pela Fundação Oswaldo Cruz (Fiocruz). < gilvaniagrang@yahoo.com.br>.

5 Enfermeira, professora titular em Enfermagem em Saúde Mental da Universidade Estadual do Ceará (Uece) e coordenadora do Doutorado em Saúde Coletiva da Uece/UFC, Fortaleza, Brasil. Doutora em Enfermagem pela Escola de Enfermagem de Ribeirão Preto/Universidade de São Paulo (EERP/USP). <maria.salete.jorge@gmail.com>. 


\section{Referências}

AYRES, José Ricardo C. M. Cuidado e humanização das práticas de saúde. In: DESLANDES, Suely Ferreira (Org.). Humanização dos cuidados em saúde: conceitos, dilemas e práticas. Rio de Janeiro: Editora Fiocruz, 2006. p. 49-83.

BARDIN, Laurence. Análise de conteúdo. Lisboa: Edições 70, 2009.

BOFF, Leonardo. Saber cuidar: ética do humano - compaixão pela terra. Petrópolis: Vozes, 1999.

BRASIL. Lei $n .^{\circ} 8.069$, de 13 de julho de 1990: Estatuto da Criança e do Adolescente (ECA). Fortaleza: Conselho Estadual dos Direitos da Criança e do Adolescente do Ceará, 1991.

Conselho Nacional de Defesa dos Direitos da Criança e do Adolescente. Resolução n. ${ }^{\circ} 41$, de 13 de outubro de 1995. Dispõe sobre os direitos da criança hospitalizada. Diário Oficial da República Federativa do Brasil, Brasília, DF, seção I, p. 16.319-16.320, 17 out. 1995.

Ministério da Saúde. Política Nacional de Humanização. Brasília, DF: Ministério da Saúde, 2004

. Ministério da Saúde. Carta dos direitos dos usuários da saúde. Brasília, DF: Ministério da Saúde, 2006.

CAPOBIANCO, Cristina Surani Mora. O corpo em off: a doença e as práticas psi na pediatria hospitalar. São Paulo: Estação Liberdade, 2003.

CECÍLIO, Luiz Carlos de Oliveira; MERHY, Emerson Elias. A integralidade do cuidado como eixo da gestão hospitalar. In: PINHEIRO, Roseni; MATTOS, Ruben Araújo de (Org.). Construção da integralidade: cotidiano, saberes e práticas em saúde. Rio de Janeiro: Abrasco, 2003. p. 197-210.

COSTENARO, Regina G. Santini; LACERDA, Maria Ribeiro. Quem cuida de quem cuida?
Quem cuida do cuidador? Santa Maria: Centro Universitário Franciscano, 2001.

DESLANDES, Suely Ferreira. Análise do discurso oficial sobre a humanização da assistência hospitalar. Ciência \& Saúde Coletiva, Rio de Janeiro, v. 9, n. 1, p. 7-14, 2004.

DESLAURIERS, Jean-Pierre; KÉRISIT, Michèle. O delineamento de pesquisa qualitativa. In: POUPART, Jean et al. (Org.). A pesquisa qualitativa: enfoques epistemológicos e metodológicos. Petrópolis: Vozes, 2008. p. 127-153.

FERREIRA, Aurélio Buarque de Holanda. Dicionário Aurélio eletrônico. Versão 3.0. Rio de Janeiro: Nova Fronteira, 1999.

FRAGA, Maria de Nazaré de Oliveira. A prática de enfermagem psiquiátrica: subordinação e resistência. São Paulo: Cortez, 1993.

GOMES, Ilvana Lima Verde. A criança hospitalizada, seus direitos e as relações interpessoais no cuidado e tratamento: caminhos e descaminhos. Tese (Doutorado em Medicina Social) - Instituto de Medicina Social, Universidade do Estado do Rio de Janeiro, Rio de Janeiro, 2007.

HEIDEGGER, Martin. Ser e tempo. Petrópolis: Vozes, 1989. Parte 1.

LEOPARDI, M. T. Metodologia da pesquisa na saúde. 2. ed. rev. e atual. Florianópolis: UFSC, 2002.

LUZ, Madel Therezinha. Fragilidade social e busca de cuidado na sociedade civil de hoje. In: PINHEIRO, Roseni; MATTOS, Ruben Araújo de (Orgs.). Cuidado: as fronteiras da integralidade. Rio de Janeiro: Abrasco, 2004. p. 9-20.

MARTINS, Maria Cezira Fantini Nogueira. Humanização da assistência e formação do profissional de saúde. Psychiatry on line Brazil, v. 8, n. 5, maio 2003. Disponível em: $<$ www.priory.com/brazil.htm $>$. Acesso em: 18 nov. 2010 
MATTOS, Rubem A. Os sentidos da integralidade: algumas reflexões acerca de valores que merecem ser defendidos. In: PINHEIRO, Roseni; MATTOS, Rubem A. (Org.). Os sentidos da integralidade na atenção e no cuidado à saúde. Rio de Janeiro: Abrasco, 2001. p. 39-64.

MINAYO, Maria Cecília S. (Org.). Pesquisa social: teoria, método e criatividade. Petrópolis: Vozes, 1993.

MORSCH, Denise Streit; ARAGÃO, Priscila Menezes. A criança, sua família e o hospital: pensando processos de humanização. In: DESLANDES, Suely Ferreira (Org.). Humanização dos cuidados em saúde: conceitos, dilemas e práticas. Rio de Janeiro: Editora Fiocruz, 2006. p. 235-260.

OLIVEIRA, Helena. Ouvindo a criança sobre a enfermidade e a hospitalização. In: CECCIM, Ricardo B.; CARVALHO, Paulo R. (Orgs.). Criança hospitalizada: atenção integral como escuta à vida. Porto Alegre: Editora da UFRGS, 1997. p. 42-55.
PINHEIRO, Roseni; GUIZARDI, Francine Lube. Cuidado e integralidade: por uma genealogia de saberes e práticas no cotidiano. In: PINHEIRO, Roseni; MATTOS, Ruben Araújo de (Orgs.). Cuidado: as fronteiras da integralidade. Rio de Janeiro: Abrasco, 2004. p. 21-36.

SÁ, Ana Cristina. O cuidado do emocional em enfermagem. São Paulo: Robe, 2001.

SILVA, H. G. F. Absenteísmo e estresse na equipe de enfermagem da emergência: causas e efeitos. Monografia (Especialização em Enfermagem do Trabalho) - Universidade Estadual do Ceará, Fortaleza, 2003.

TRIVIÑOS, Augusto Nibaldo S. Introdução à pesquisa em ciências sociais: a pesquisa qualitativa em educação. São Paulo: Atlas, 1987.

WINNICOTT, Donald W. Pensando sobre crianças. Porto Alegre: Artes Médicas, 1997.

Recebido em 20/10/2008

Aprovado em 09/04/2010 